\title{
HOMOPOLAR GENERATOR POWERED HIGH FIELD MAGNET EXPERIMENT FOR THE IGNITEX FUSION DEVICE
}

\author{
By: \\ M. D. Werst \\ G. W. Brunson \\ M. D. Driga \\ K. T. Hsieh \\ R. L. Sledge \\ W. F. Weldon \\ H. H. Woodson
}

Proceedings, Seventh IEEE Pulsed Power Conference, Monterey, California, June 11-14, 1989, pp. 219-223

PN - 155

Center for Electromechanics

The University of Texas at Austin

PRC, Mail Code R7000

Austin, TX 78712

(512) 471-4496 


\section{HOMOPOLAR GENERATOR POWERED HIGH FIELD MAGNET EXPERIMENT FOR THE IGNITEX FUSION DEVICE}

M.D. Werst, G.W. Brunson, M.D. Driga, K.T. Hsieh, R.L. Sledge,W.F. Weldon and H.H. Woodson Center for Electromechanics The University of Texas at Austin Balcones Research Center Building 133

Austin, TX 78758-4497

\section{$\underline{\text { Abstract }}$}

The design of a scaled down prototype of the IGNITEX (Texas Ignition Experiment) toroidal field (TF) magnet is discussed. The IGNITEX concept is a single-turn tokamak designed to produce and control an ignited plasma with ohmic heating alone[1,2]. The objective of the IGNITEX Technology Demonstrator (ITD) is to design, fabricate and test the operation of a single turn, 20 tesla, toroidal field coil powered by a homopolar generator (HPG) power supply. An existing 60 MJ, 9MA homopolar power supply located at the Center for Electromechanics at The University of Texas at Austin (CEM-UT) will be used to drive the experiment[3]. Test results from the ITD program will validate the technology required to generate a 20 tesla, toroidal magnetic field in the necessary geometry to produce fusion by ohmic heating alone.

\section{Introduction}

Production of a controlled thermonuclear fusion reaction represents a major scientific and technical challenge which has eluded mankind for the last four decades. The challenge is never-the-less worthwhile since fusion represents a virtually inexhaustible energy source. IGNITEX was conceived at the The University of Texas at Austin (UTA) by Marshall N. Rosenbluth, William F. Weldon, and Herbert H. Woodson.[1]

The IGNITEX concept is a single-turn tokamak designed to produce and control an ignited plasma with ohmic heating alone. Detailed plasma physics analysis indicates that IGNITEX provides an ample ignition margin and a passive means of controlling the ignited phase of the experiment [4]. Nonconventional magnet and power supply technologies make the design possible. The proposed high-strength toroidal magnet system is designed to produce an on-axis field of $20 \mathrm{~T}$ The IGNITEX single-turn coil tokamak requires a very high current (150 $\mathrm{MA})$, low voltage (10 V) power supply[5]. Homopolar generators can satisfy these requirements inexpensively. A single turn configuration eliminates the turn-to-turn insulation, increasing the current-carrying capability of the coil.

A magnet scale of 0.06 has been selected for the ITD simply because of the linear relationship between scaling factor and the current required to achieve a $20 \mathrm{~T}$ field in a single turn configuration. The Balcones HPG power supply shown in figure 1 is rated at $60 \mathrm{MJ}$ $9 \mathrm{MA}$ at $100 \mathrm{~V}$, therefore the scaling factor of $9 \mathrm{MA} / 150 \mathrm{MA}$ or 0.06 was selected. A pulse transformer was considered to step up the generator current to accommodate a larger scale but inefficiencies in the transformer and excessive cost made this option unattractive. In addition, directly coupling the TF coil to the HPGs is more representative of the full scale IGNITEX. A second prototype with a scaling factor of 0.12 will succeed the 0.06 scale prototype and will operate at $10 \mathrm{~T}$ when driven directly with the homopolar generator power supply. The 0.12 scale TF coil is intended to demonstrate scaling relationships as well as serve as the load for a proposed $1 \mathrm{GJ}$ homopolar module[5]. Table 1 compares the critical parameters for the full-scale IGNITEX TF coil and the 0.06 scale TF coil. Stresses in the 0.06 scale coil are representative of stresses in the full scale TF coil even though the current density is a function of the square of the scaling factor. In addition, as long as the time scaling factor is the square of the geometric scaling factor, the temperature, magnetic induction and Mises stresses in the scaling model are an image of those for the full scale model.

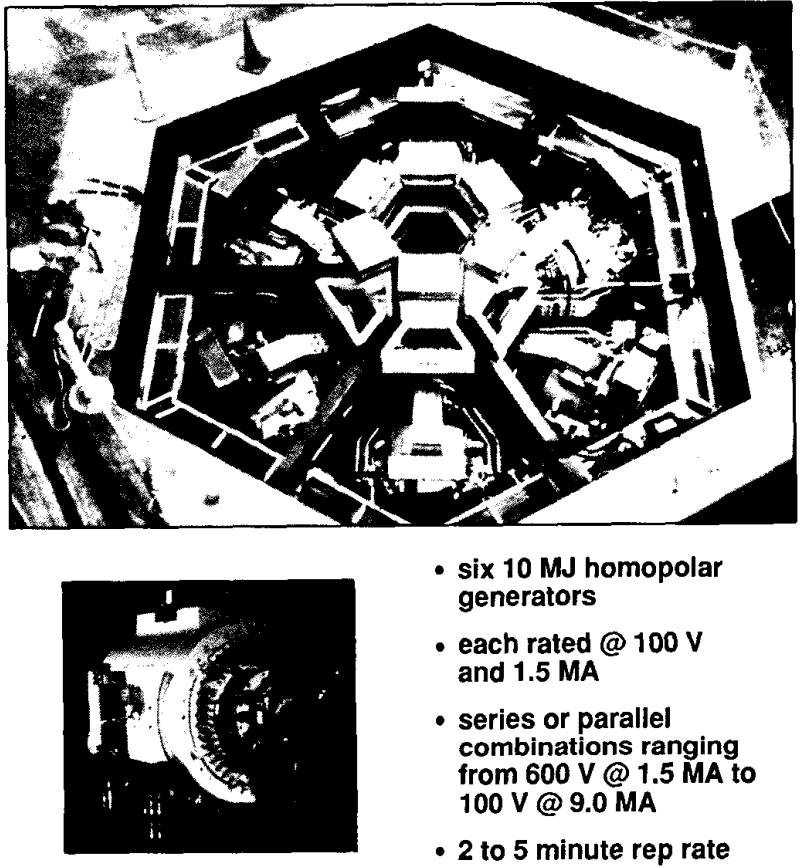

Figure 1. Balcones homopolar generators

Table 1. Critical parameters of full-scale and prototype IGNITEX TF coils

\begin{tabular}{|c|c|c|}
\hline & $\begin{array}{l}\text { IGNITEX } \\
\text { TF COIL }\end{array}$ & $\begin{array}{c}\text { TECHNOLOGY } \\
\text { DEMONSTRATION } \\
(9 / 150 \text { or } 0.06 \text { scale })\end{array}$ \\
\hline MAJOR RADIUS & $1.5 \mathrm{~m}$ & $9 \mathrm{~cm}$ \\
\hline $\begin{array}{l}\text { MAGNETIC ENERGY } \\
\text { STORED }\end{array}$ & $3.7 \mathrm{GJ}$ & $800 \mathrm{~kJ}$ \\
\hline PULSE WIDTH & $10 \mathrm{~s}$ & $100 \mathrm{~ms}$ \\
\hline PEAK CURRENT & $150 \mathrm{MA}$ & 9 MA \\
\hline $\begin{array}{c}\text { MAX. STRESS } \\
\text { (vonMises) }\end{array}$ & $78 \mathrm{ksi}$ & $84 \mathrm{ksi}$ \\
\hline $\begin{array}{l}\text { TEMPERATURE } \\
\text { @ Peak Stress }\end{array}$ & $87^{\circ} \mathrm{C}$ & $176^{\circ} \mathrm{C}$ \\
\hline AXIAL PRELOAD & $65,000 \mathrm{~T}$ & $420 \mathrm{~T}$ \\
\hline NO. OF SECTORS & 12 & 6 \\
\hline MATERIALS & D.S.C. & $\mathrm{Be} \mathrm{Cu}$ \\
\hline
\end{tabular}




\section{Description of Experiment}

The 0.06 scale toroidal field coil as it will be located in the CEM-UT HPG pit is shown in figure 2. The design philosophy of the magnet has been to use materials with the highest strength and electrical conductivity available and preload it as much as possible. Unlike conventional toroidal field coils that use multiple turns of the conductor, the single turn coil eliminates the need for turn-to-turn insulation and therefore better utilizes the available area for stress and thermal management. Precooling the coil to liquid nitrogen temperature permits the magnet to operate for a longer period without exceeding material properties.

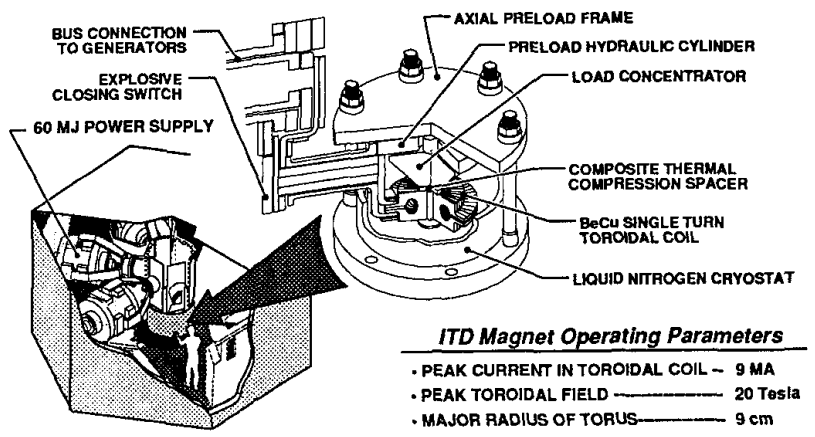

Figure 2. ITD as located in the CEM-UT $60 \mathrm{MJ}$ Homopolar Generator pit

High magnetic and thermally generated stresses in the TF coil require a very high axial preload system to prevent it from exceeding the yield strength of the material. Preload requirements for the 0.06 scale are 420 tons in order to maintain an average axial compressive load of $50 \mathrm{ksi}$ over the inner leg area of the coil. The preload is applied hydraulically to the inner leg of the TF coil via a composite thermal compression spacer at the top and bottom of the coil. An external frame provides the axial containment and is also used to support the structure. The hydraulic system must maintain the preload through the discharge, compensating for axial strain and thermal growth. A second preload is applied radially at the top and bottom of the TF coil to hold the coil sectors together. The radial preload is applied by two rings which are thermally assembled over the coil sectors.

The ITD experiment will be located in the base of the CEM-UT HPG pit permitting the busbars to feed the device from above (see figure 2). This arrangement simplifies the liquid nitrogen cryostat by eliminating cryogenic seals on the busbars. Heating elements located on the busbars will prevent condensation from forming in the generators. The TF coil, consisting of six $60^{\circ}$ sectors will be connected to the six HPGs in a parallel configuration as shown in figure 3 . Although access to the ITD experiment will be limited by locating it in the HPC pit, the location minimizes the length of bus between the generators and the TF coil and by designing a removable joint in the busbars, permits other experiments above the pit to utilize the generators.

Due to the geometry and layout of the existing busbars in the HPG pit, the circuit parameters of this experiment are for the most part fixed. The inductance of the HPGs and the bus leading up to where the TF coil will be attached dominate the equivalent inductance for the circuit. A scaled pulse for the 0.06 scale TF coil would be $36 \mathrm{~ms}$ long with an $18 \mathrm{~ms}$ flat-top as shown in figure 4 . A simulated HPG discharge current profile is superimposed showing an estimated pulse width in excess of $100 \mathrm{~ms}$. Electromagnetic loading at peak current will be representative of the full scale IGNITEX TF coil but much more energy is deposited in the prototype after peak current. This results in thermal stresses at the end of the pulse that exceed the electromagnetic loading at peak current. Should the actual circuit inductance exceed those estimated for the generation of the current profile, a dump circuit may have to be included to reduce the energy in the coil.

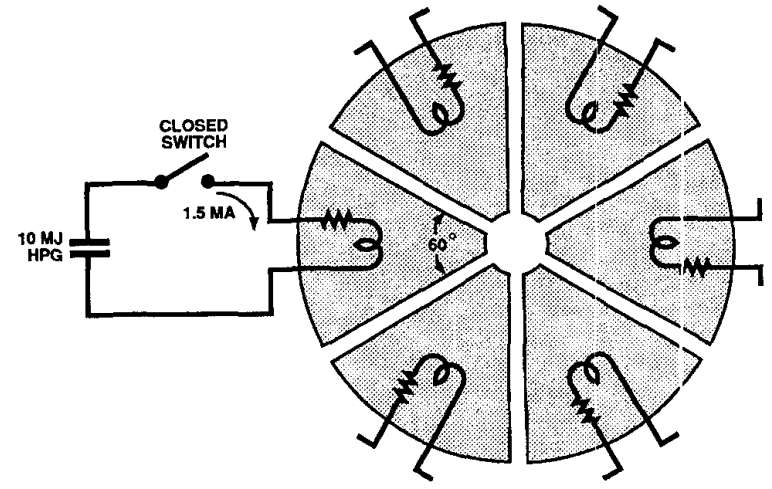

4501.0012

Figure 3. ITD power supply layout

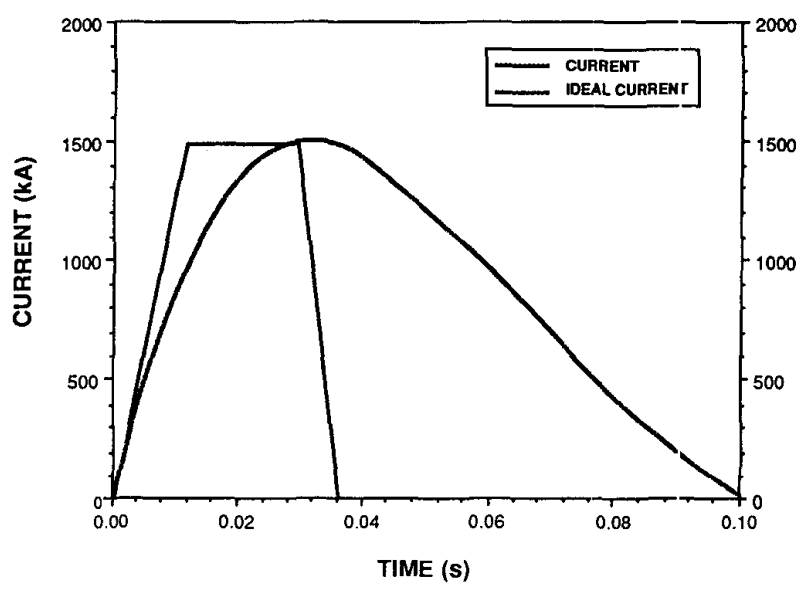

4501.0038

Figure 4. ITD current profiles--simulated and ideal

Each HPG $/ 60^{\circ}$ TF coil sector will have an explosive closing switch to initiate the discharge The brushes of the balconies $10 \mathrm{M}$ ] HPGs were designed to initiate discharges into high inductive loads and therefore have a relatively low $\mathrm{di} / \mathrm{dt}$ rating of $8 \mathrm{MA} / \mathrm{s}$. Activation time for the pneumatically activated trushes is approximately $25 \mathrm{~ms}$ with a jitter of $\pm 5 \mathrm{~ms}[3]$. Since the low inductance ITD experiment has a di/dt of $50 \mathrm{MA} / \mathrm{s}$ with a current rise time of $30 \mathrm{~ms}$, faster switches are required. An existing switch, which is well proven and frequently used in railgun experiments, will be scaled up to accommodate the action integral $\left(\mathrm{i}^{2} \mathrm{dt}=11 \times 10^{10} \mathrm{~A}^{2} \mathrm{~s} /\right.$ generator) of the ITD experiment. A typical closing time for this switch design is $100 \mu \mathrm{s}$ with a maximum jitter of $\pm 15 \mu$ s and $\mathrm{di} / \mathrm{dt}$ of $5 \mathrm{GA} / \mathrm{s}[6]$.

\section{TF Coil Design}

The electromechanical analysis of the single turn coil consists of the use of a finite element program (TEXCOR)[7] to solve a set of coupled electrical circuit, magnetic diffusion and thermal diffusion equations with temperature dependent properties. TEXCOR provides temperatures and magnetic body force densities for a three dimensional, finite element stress analysis of the magnet structure. 
Preliminary analysis of the IGNITEX TF coil was performed with dispersion strengthened copper (GlidCop Al-15) as the magnet material. Material testing performed on the GlidCop material in practical plate thicknesses has revealed strength levels that do not meet design requirements. Other materials have been investigated in an attempt to find an existing material that would meet the design requirements of the single turn TF coil. Beryllium copper (Brush Wellman Alloy \#3 HT C17510) has demonstrated an electrical conductivity of $64 \%$ IACS and a yield strength of $108 \mathrm{ksi}$ at $20^{\circ} \mathrm{C}$ in both transverse and longitudinal directions. Of concern of course, was the increase in the temperature of the inner leg region of the coil as a result of the decrease in electrical conductivity. In addition, beryllium copper has only a factor of two increase in electrical conductivity at liquid nitrogen temperature. Use of beryllium copper results in a maximum temperature of $186^{\circ} \mathrm{C}$ and a peak Mises stress of $86 \mathrm{ksi}$ at peak electromagnetic loading. Thermally generated stresses at the end of the pulse are more severe. Figures 5 and 6 shows a peak Mises stress of $96 \mathrm{ksi}$ at the end of the pulse with a peak temperature of $220^{\circ} \mathrm{C}$ at the $O D$ of the inner leg. Stresses and temperatures are overall higher for the beryllium copper but are within the materials capability even with additional heating due to an elongated current pulse. Figure 7 shows a stress contour plot of a prototype TF coil plate at peak electromagnetic loading.

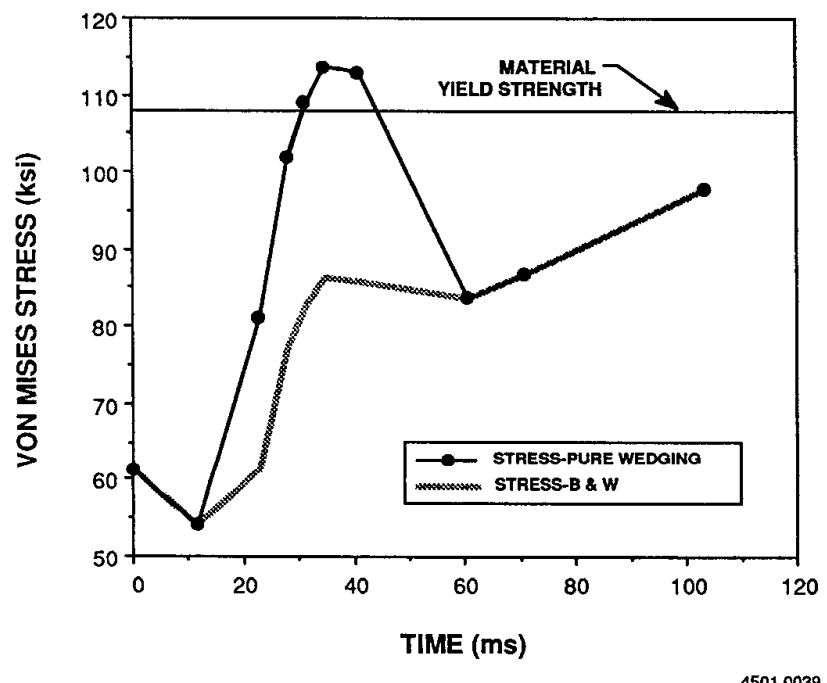

Figure 5. Peak Mises stresses in prototype toroidal field coil--pure wedging and bucking \& wedging

Beryllium copper as the conductor for the TF coil is attractive for several reasons. First, the magnet operates at a lower percentage of the materials yield strength than it would with the dispersion strengthened copper. Secondly, beryllium copper is a precipitationhardened alloy and unlike the dispersion strengthened copper, does not rely on a high degree of cold work to obtain its strength. A highly cold worked piece of dispersion strengthened copper requires a post-heat treatment to relieve residual stresses otherwise the material is unstable and obtaining high flatness tolerances is extremely difficult. The post-heat treatment reduces the yield strength of the material by about 2-3 ksi. Finally, beryllium copper has well characterized thermophysical and mechanical properties and is available in the plate sizes required for the full scale IGNITEX in thicknesses up to $6 \mathrm{in}$. Table 2 gives material properties for dispersion strengthened copper (GlidCop Al-15) and beryllium copper (Brush Alloy \#3 HT).

Beryllium copper has been selected as the material for the prototype IGNITEX TF coils and based on today's material technology and is recommended as the material for the full scale IGNITEX. High strength and high electrical conductivity alloys are continually being improved upon and therefore other conductor alloys will remain in consideration until procurement for the full scale magnet is required.

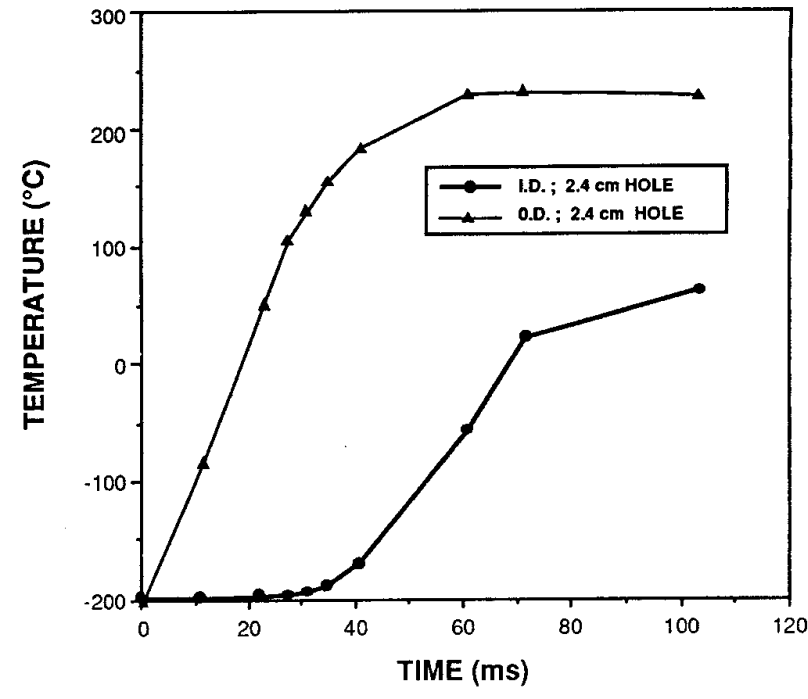

4501.0040

Figure 6. Temperature of prototype TF coil at I.D. and O.D. of inner leg
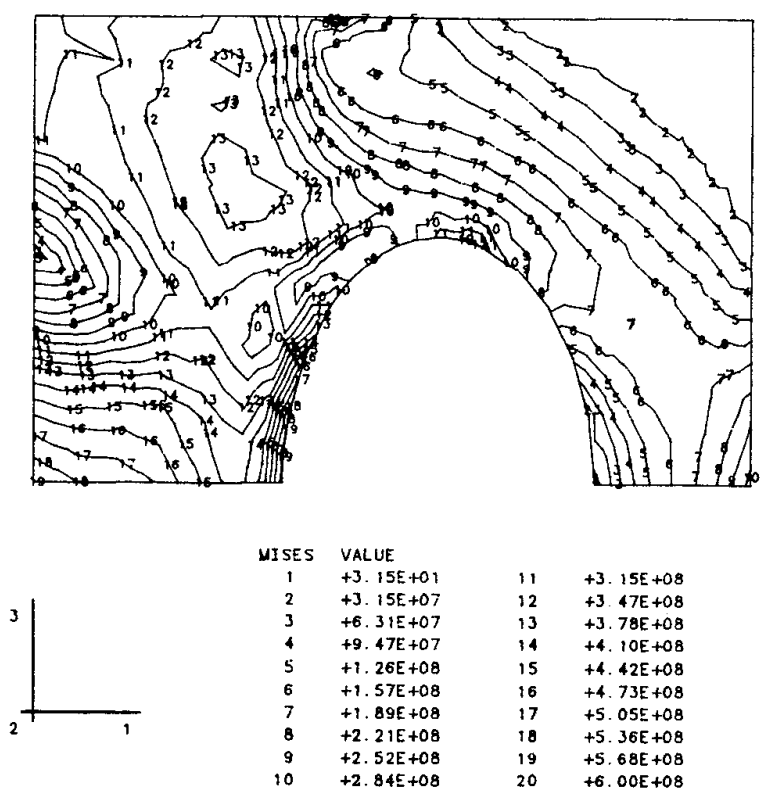

4501.0041

Figure 7. Mises stress contour plot of prototype TF coil plate at peak electromagnetic loading

Inward radial forces on the tapered coil plates causes the plates to "wedge" against each other while the inward. radial force also causes each plate to "buck" against the central support post. An ideal operating stress state for a TF coil is one which utilizes a combination of "bucking and wedging" [8]. Uncertainties in a TF coil's design such as a compliant magnet structure, gaps between plates and thermal gradients may inhibit achieving an optimum balance. Several features of the single turn TF coil design minimize the uncertainties or nonideal effects and distinguish it from conventional tokamak designs. These features are: 1) a well characterized and "noncompliant" material in the inner neck region of the TF coil as a 
Table 2. Material properties of dispersion strengthened copper and beryllium copper

\begin{tabular}{|c|c|c|}
\hline PROPERTY/ALLOY & $\begin{array}{l}\text { DISPEASIN } \\
\text { STRENGTHENED } \\
\text { COPPER AI- } 15\end{array}$ & $\begin{array}{l}\text { BEFYYLIUM } \\
\text { COPPEA } \\
\text { ALLOY } * 3 \mathrm{HT}\end{array}$ \\
\hline Thermal Expansion (in./in.fF-10E-6)* & 10.9 & 9.8 \\
\hline Conductivity @ Room Temp. (\%/ACS) & 92 & 63 \\
\hline Conductivity Ratio (Cond. LN ${ }^{2} /$ Cond. Rm Temp.) & 4.6 & 2 \\
\hline Therms I Conductivity $\left(\mathrm{W}^{\prime} \mathrm{M}^{\circ} \mathrm{K}\right)^{*}$ & 365 & 249 \\
\hline Specific Heat $\left(\mathrm{J} / \mathrm{kg}{ }^{\circ} \mathrm{K}\right)^{*}$ & 385 & 334 \\
\hline Yield Strength (ksi)* & 67 & 110 \\
\hline Modulus of Elasticity (Msl) & 17 & 20 \\
\hline Percent Cold Work Required (\%) & 75 & 37 \\
\hline Cost /lb. (dollars) & 25 & 15 \\
\hline Max. Plate Thickness (in.) & 0.63 & 6 \\
\hline
\end{tabular}

result of eliminating turn-to-turn insulation, 2) a minimum tolerance "stack-up" in toroidal plate assembly, and 3) a solid bucking cylinder in which the shape and material properties may be selected to best suit the combined stress state at peak loading.

Figure 5 shows Mises stresses for the pure wedging and the combined stress state of bucking and wedging. A pure wedging stress state is much more desirable than pure bucking but stresses close to peak electromagnetic loading still exceed the yield strength of the material. By contouring the bucking post, a combined stress state may be achieved at peak loading reducing the Mises stresses. The TF coil is initially in a pure wedging state. As the magnet is energized, the inner leg is displaced inward toward the bucking post. Correctly sizing the bucking post contour is critical in order for the TF coil to make contact with it just prior to peak loading. To do this the radial displacement of the coil must be accurately predicted.

\section{Fabrication and Assembly}

Fabrication and assembly procedures are essential to the success of the IGNITEX TF coil demonstration. The toroidal field coil assembly incorporates six, $60^{\circ}$ subassemblies. One TF coil wedge is machined from an 1.25 in. thick beryllium copper plate. The plates are machined to an angle of $10^{\circ} 1^{\prime}$ so that when stacked in the $60^{\circ}$ subassemblies, they may be remachined to eliminate angular tolerance stackups. Six TF coil plates of a $60^{\circ}$ sector are stacked together and for ease of assembly the plates are temporarily bolted together (see figure 8). The plates are machined and toleranced to ensure that the plates are in intimate contact in the inner leg region. Electrical insulation between TF coil sectors consists of a 1/2 mil sheet of mylar $\$$ to break up eddy currents in the longitudinal direction. Three of the $60^{\circ}$ sectors are bolted together and the two exposed surfaces are machined planar to each other. Once this is done to both halves of the TF coil, the two sections are assembled. The final assembly of the toroid has only the flatness tolerance stack up; angular tolerances are negated by this assembly technique. The bore of the TF coil is filled with a foam filler material to displace liquid nitrogen and prevent over pressurizing this volume during a discharge. Instrumentation to measure field levels, current, temperature rise and strain are is also installed. An assembly fixture is used to assemble the six coil sectors and to machine the radial and axial preload surfaces. The two radial preload rings are then thermally assembled around the TF coil. With a known radial preload applied to the coil plates by the preload rings, the bore of the coil may be machined and the bucking cylinder shrunk into place.

\section{Conclusion}

Test results from the ITD program will accomplish several things. First, the analytical computer model's predictions of displacements, temperature rise and field levels will be compared to actual measurements, proofing the complex model. Secondly, fabrication techniques and assembly procedures developed for the prototype may be applied to the full scale IGNITEX. Finally, the Program
- 36 ea, $10^{\circ} 5^{\prime}$, TF coil plates

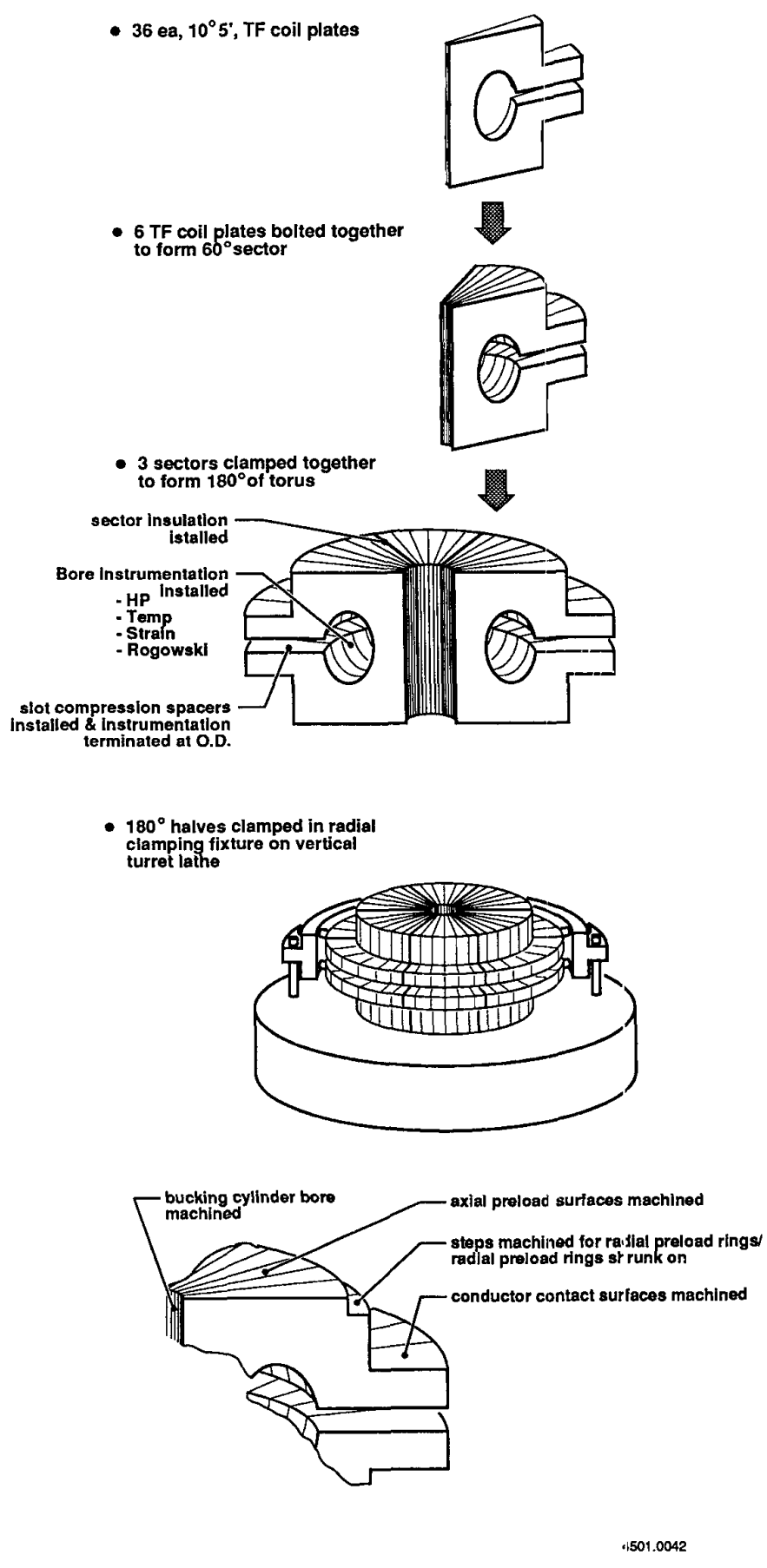

Figure 8. TF coil assembly procedure

IGNITEX Technology Demonstrator will validate the technology to generate a $20 \mathrm{~T}$ toroidal magnetic field using homopolar generators as the power supply.

\section{Acknowledgement}




\section{References}

[1] W.F. Weldon and H.H. Woodson, "Fusion Engineering Machine", Texas Atomic Energy Foundation (TAERF) Report No. 35, October 1982.

[2] M.N. Rosenbluth, W.F. Weldon, H.H. Woodson, "Basic Design Report of the Fusion Ignition Experiment (IGNITEX)," presented in Texas Atomic Energy Foundation Project Progress Report, March 1987.

[3] J.H. Gully, D.J. Hildenbrand, and W.F. Weldon, "Balcones Homopolar Generator Power Supply," IEEE Transactions on Magnetics Volume 25 No. 1, January 1989.

[4] R. Carrera, E. Montalvo, and M.N. Rosenbulth, "Fusion Ignition Experiment," Institute for Fusion Studies Report IFSR N. 314, The University of Texas at Austin, March 1988.

[5] W.A. Walls, W.F. Weldon, H.H. Woodson, M.D. Driga, and J.H. Gully, "Pulsed Homopolar Generator Power Supplies for the IGNITEX Experiment," 12th Symposium on Fusion Engineering, Monterey, CA, October 1987.

[6] R.L. Sledge, J. Hahne, "Experimental Data on High Power Explosive Opening and Closing Switches at CEM-UT," 7th IEEE Pulsed Power Conference, Monterey, CA, June 1989.

[7] K.T. Hsieh, Finite element analysis code for solving axisymmetric magnetic, thermal diffusion equations, Center for Electromechanics, The University of Texas at Austin, 1986.

[8] D.B. Montgomery, J. Chen, and H. Becker, "Bucking and Wedging Considerations for CIT," May 1987. 